\section{Commentary: Bicuspid aortic valve and experts' consensus; more than the sum of its parts}

\author{
Eric E. Roselli, MD
}

The whole is greater than the sum of the parts.

-Aristotle, Metaphysics

People with $<3$ cusps to their aortic valve are typically diagnosed with bicuspid aortic valve (BAV), but the spectrum of bicuspidness is vast and multidimensional. BAV results from an error in embryologic development. Where, when, and how this occurs during aortic valve, left ventricular outflow tract, and aortic root maturation determines morphology and the severity of pathology.

As management of this condition evolves, so too must our appreciation for the details. When surgical valve replacement or commissurotomy were the only treatment options for BAV, nuances of pathology were most relevant to researchers focused on discovery. More recently, valve repair has become a durable option for select patients with aortic insufficiency. ${ }^{1}$ Its success demands a better appreciation for factors such as ventriculoaortic discontinuity; anulus shape and dimension; aortic root architecture; and cusp size, shape, and orientation. We are now seeing transcatheter aortic valve replacement (TAVR) increasingly applied to older patients with BAV. When TAVR was new, we quickly learned that its success depended on a keen understanding of the patient-prosthesis interface. This issue is even more important for patient selection in TAVR for BAV.

An esteemed group of more than 50 world experts on the topic of BAV spent nearly 3 years writing a thorough consensus document focused on the nomenclature and classification of congenital BAV disease. ${ }^{2}$ The

From the Department of Thoracic and Cardiovascular Surgery; Heart, Vascular, and Thoracic Institute, Cleveland Clinic, Cleveland, Ohio.

Disclosures: The author reported no conflicts of interest.

The Journal policy requires editors and reviewers to disclose conflicts of interest and to decline handling or reviewing manuscripts for which they may have a conflict of interest. The editors and reviewers of this article have no conflicts of interest.

Received for publication Jan 17, 2021; revisions received Jan 17, 2021; accepted for publication Jan 20, 2021; available ahead of print Jan 28, 2021.

Address for reprints: Eric E. Roselli, MD, Department of Thoracic and Cardiovascular Surgery, Heart, Vascular, and Thoracic Institute, Cleveland Clinic, 9500 Euclid Ave, Desk J4-1, Cleveland, OH 44195-5108 (E-mail: RosellE@ ccf.org).

J Thorac Cardiovasc Surg 2021;162:798-9

$0022-5223 / \$ 36.00$

Copyright (c) 2021 by The American Association for Thoracic Surgery

https://doi.org/10.1016/j.jtcvs.2021.01.070

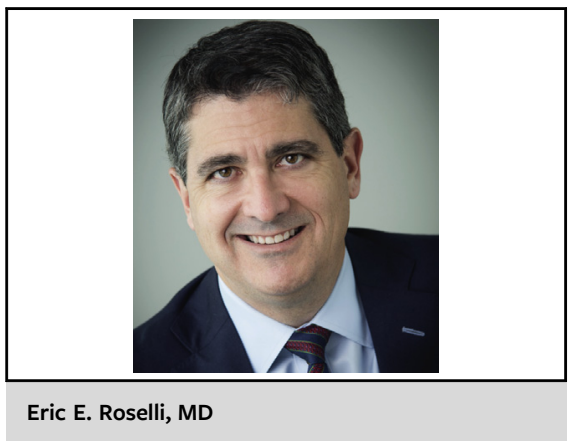

CENTRAL MESSAGE

Multidisciplinary treatment of congenital bicuspid aortic valve demands attention to detail across the spectrum of bicuspidness. Standard nomenclature can improve precision of care for the condition.

multidisciplinary group includes cardiologists, surgeons, interventionalists, pathologists, geneticists, and imaging specialists. They describe various systems (at least 11) used to categorize these patients. The stage was set for heterogeneity and potential confusion, but they worked together from multiple perspectives to arrive at consensus.

The objective of a nomenclature and classification system is to optimize communication and collaboration by providing simplicity and standardization. The proposed International Consensus Classification system uses an English language method of nomenclature that includes cusp differentiation between fused $\mathrm{BAV}, 2$-sinus $\mathrm{BAV}$, and partial fusion BAV; details about valve function and symmetry (relevant for valve repair) and a description of aortopathy phenotype ( 3 types as validated by machine learning ${ }^{3}$ ) with or without coarctation. BAV is too complex of a subject to simplify. If the goal is to improve communication and collaboration around the topic of congenital aortic valve disease, they have taken a great first step.

To improve clarity, the authors eliminate congenital unicuspid aortic valve (ie, Sievers type 2) from this conversation. Congenital unicuspid aortic valves are encountered intraoperatively more often than predicted by preoperative imaging. ${ }^{4}$ The proposed nomenclature and classification guidance provided by this document could be applied to unicuspid patients too. It is quite common for a patient to come to the operating room with a diagnosis of BAV and on inspection have a unicuspid valve with 3 sinuses, fused right left and noncoronary cusps 
with a single left/noncommissure, asymmetry, and a root phenotype aortopathy. Most of these patients are young adults faced with more difficult perioperative decisions about timing and treatment than a typical BAV patient.

Our tools for understanding this complex condition will continue to improve. We will gain a better understanding of the genetics and embryologic processes of maldevelopment. New imaging techniques allow for the quantitative fusion of anatomic and physiologic details. We are learning how biomechanics and mechanotransduction lead to the progression of pathology. Improved artificial intelligence systems will identify patterns from imaging and statistical signals. As our knowledge improves, so will our need to communicate across disciplines so that each individual patient we meet can receive the best precision care for his or her congenital aortic valve condition.

\section{References}

1. Zeeshan A, Idrees JJ, Johnston DR, Rajeswaran J, Roselli EE, Soltesz EG, et al Durability of aortic valve cusp repair with and without annular support. Ann Thorac Surg. 2018;105:739-48.

2. Michelena HI, Della Corte A, Evangelista A, Maleszewski JJ, Edwards WD, Roman MJ, et al. International Consensus Statement on nomenclature and classification of the congenital bicuspid aortic valve and its aortopathy, for clinical, surgical, interventional and research purposes. J Thorac Cardiovasc Surg. 2021;162:e383-414.

3. Wojnarski CM, Roselli EE, Idrees JJ, Zhu Y, Carnes TA, Lowry AM, et al Machine-learning phenotypic classification of bicuspid aortopathy. J Thorac Cardiovasc Surg. 2018;155:461-9.e4.

4. Zhu Y, Roselli EE, Idrees JJ, Wojnarski CM, Griffin B, Kalahasti V, et al. Outcomes after operations for unicuspid aortic valve with or without ascending repair in adults. Ann Thorac Surg. 2016;101:613-9.
See Article page e383.

\section{Commentary: Parley at the summit}

Vicente Orozco-Sevilla, MD, and Joseph S. Coselli, MD

Drawing from his fascination with Mount Everest expeditions, Winston Churchill used the term summit to describe a high-level meeting between international powers to define the world order in the 20th century. A distinguished list of coauthors, many of whom are international leaders in bicuspid aortic valve (BAV) disease, are to be commended for their efforts to provide us with a new system of nomenclature and classification for patients with a BAV. ${ }^{1}$ The authors intend to standardize language for anatomy, diagnosis,

\footnotetext{
From the Division of Cardiothoracic Surgery, Michael E. DeBakey Department of Surgery, Baylor College of Medicine; Section of Adult Cardiac Surgery, Department of Cardiovascular Surgery, Texas Heart Institute, and Department of Cardiovascular Surgery, CHI St Luke's Health-Baylor St Luke's Medical Center, Houston, Tex.

Disclosures: The authors reported no conflicts of interest.

The Journal policy requires editors and reviewers to disclose conflicts of interest and to decline handling or reviewing manuscripts for which they may have a conflict of interest. The editors and reviewers of this article have no conflicts of interest.

Received for publication Jan 15, 2021; revisions received Jan 15, 2021; accepted for publication Jan 19, 2021; available ahead of print Jan 28, 2021.

Address for reprints: Joseph S. Coselli, MD, Division of Cardiothoracic Surgery,

Michael E. DeBakey Department of Surgery, Baylor College of Medicine, One

Baylor Plaza, BCM 390, Houston, TX 77030 (E-mail: jcoselli@bcm.edu).

J Thorac Cardiovasc Surg 2021;162:799-800

$0022-5223 / \$ 36.00$

Copyright (c) 2021 by The American Association for Thoracic Surgery

https://doi.org/10.1016/j.jtcvs.2021.01.072
}

Check for updates

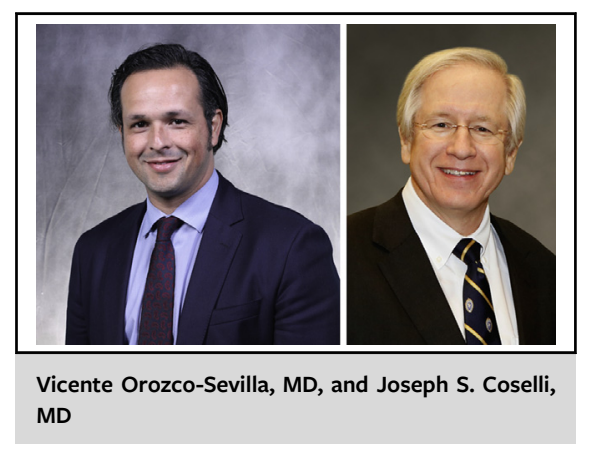

CENTRAL MESSAGE

This new nomenclature and classification system for patients with a bicuspid aortic valve aims high but its complexity may be challenging in clinical settings.

treatment, and data collection in such patients, reflecting recently gained ground in our evolving understanding of this complex disease from genetic, hemodynamic, and clinical standpoints.

With a prevalence of $1 \%-2 \%$ in the general population, ${ }^{2} \mathrm{BAV}$ disease is the most common congenital cardiovascular malformation and is seen relatively often by surgeons and clinicians in their daily practice. Its heterogeneous presentation includes a wide spectrum of conditions, such as pure aortic valve stenosis, endocarditis, 